\title{
ANNOTATIONS
}

\section{Italian Ophthalmic Society}

The Italian Ophthalmic Society held its third Congress in October of this year at Rome. The Society is the successor of the old Society which expired in 1910. The new Society is receiving universal support from all Italian Ophthalmologists and may anticipate a long and successful career. In addition to the publication of reports of the Congress, arrangements have been made with the Annali di Ottalmologia to issue individual papers. $\Lambda$ notable feature of the Society is the number of valuable prizes that have been offered for competition. In the report sent to us the credit of the organization of the Society is given to Professor Cirincione, the well-known ophthalmologist of Rome, and the editor, for many years, of the Annali di Ottalmologia.

The meeting was very well attended and numerous papers of considerable interest were read. We hope to give our readers abstracts of some of these at a later date.

\section{Société Roumaine d'Ophtalmologie}

We had occasion to refer in our number of November, 1926, to the foundation of the Society of Ophthalmology in Italy which occurred in the year 1924, and whose proceedings for the year 1925 , we have briefly reviewed. We have now to congratulate another country, Roumania, on the foundation of a similar society. The first Congress was held at Bucharest in 1924, but, owing to technical and financial difficulties, their proceedings have only recently appeared. From the introduction to their proceedings we learn that the Society was founded first in 1922. The present volume of transactions is, in large part, taken up with a discussion on trachoma, in which Professor Michail deals with the aetiology, infectivity and pathogenesis of the disease; Professor Hélène Puscariu with the symptoms, diagnosis and clinical forms; Professor Manolesco, the President of the Society, with the frequency in Roumania, its treatment and prophylaxis: and Colonel Panaitesco with trachoma as it occurs in the Roumanian army. Abstracts of these papers will be found on subsequent pages of this number of our journal.

The founding of these national societies is a sign of healthy life in the ophthalmological world, and will render more easy the task 